Article

\title{
How to Produce and Measure Throughput Legitimacy? Lessons from a Systematic Literature Review
}

\author{
Vincent Caby and Lise Frehen* \\ Institute of Political Science Louvain-Europe, Catholic University of Louvain, 1348 Louvain-La-Neuve, Belgium; \\ E-Mails: vincent.caby@uclouvain.be (V.C.), lise.frehen@uclouvain.be (L.F.) \\ * Corresponding author
}

Submitted: 15 January 2021 | Accepted: 19 February 2021 | Published: 31 March 2021

\begin{abstract}
After two decades of research on throughput legitimacy, making sense of the stock of accumulated knowledge remains a challenge. How can relevant publications on throughput legitimacy be collected and analysed? How can the level of throughput legitimacy be measured? Which policy activities contribute to the production of throughput legitimacy? To answer these questions, we designed and implemented an original systematic literature review. We find that the measurement of the level of throughput legitimacy introduces a number of problems that call for the systematic and rigorous use of a more complete set of precise, specific indicators to advance the theory of throughput legitimacy. A number of participatory decision-making activities contribute to the production of throughput legitimacy. Engaging in these activities is not without risk, as variations in throughput legitimacy affect input and output legitimacy. To prevent vicious circles, lessons can be drawn from the literature on collaborative governance and decision-makers' strategies to support effective collaboration between stakeholders.
\end{abstract}

\section{Keywords}

citation network analysis; collaborative governance; legitimacy; quantitative text analysis; systematic literature review; throughput legitimacy

\section{Issue}

This article is part of the issue "Access or Excess? Redefining the Boundaries of Transparency in the EU's Decision-Making" edited by Camille Kelbel (Lille Catholic University, France), Axel Marx (University of Leuven, Belgium) and Julien Navarro (Lille Catholic University, France).

(C) 2021 by the authors; licensee Cogitatio (Lisbon, Portugal). This article is licensed under a Creative Commons Attribution 4.0 International License (CC BY).

\section{Introduction}

After two decades of research on the concept of throughput legitimacy, making sense of the stock of accumulated knowledge remains a challenge. How can relevant publications on throughput legitimacy be collected and analysed? How can the level of throughput legitimacy be measured? Which policy activities contribute to the production of throughput legitimacy? These are the theoretical and methodological questions we address in this article.

The concept of throughput legitimacy derives from the normative discussion on the democratic deficit of the EU and other international organisations (IOs). Following the 1992 public debate on the Maastricht Treaty, Scharpf
(1997, 1999) distinguished two modes of production of democratic legitimacy: 'Input legitimacy' results from policy decisions based on citizens' preferences, and 'output legitimacy' derives from the achievement of policy goals in line with citizens' interests. In the early 2000s, scholars discussed the effects of globalisation and the growing role of IOs and other forms of cooperative governance on the production of democratic legitimacy (Papadopoulos, 2003; Zürn, 1998, 2000). Papadopoulos (2003, pp. 482-484) conceived of the idea of 'throughput legitimacy' as a synonym of procedural fairness: Procedures "that permit citizens to express their views" and that "can enhance the acceptance of decisions, no matter their content." For Zürn (1998, p. 240), through- 
put refers to the democratic principles governing the decision-making process.

Throughput legitimacy, as a third mode of production of legitimacy pertaining to the quality of the governance process, gained prominence in the 2010s. For Steffek (2019), this was due to the proceduralist turn in political science-a shift in scholars' attention from the content of decisions to the process and procedures of decision-making. We believe that this was also due to the conceptual work of Risse and Kleine (2007) and Schmidt (2013). The latter provided more operational definitions of throughput legitimacy which facilitated its application by scholars.

A bibliographic search provides a good illustration of the prominence of the concept. In January 2020, we searched the Scopus database and found 98 journal articles and book chapters with the keyword 'throughput legitimacy' in their metadata.

The challenge remains to make sense of this stock of knowledge. A symposium organised in 2017 provided a first opportunity to answer this question. In their introduction, Schmidt and Wood (2019) pointed out that the concept had been applied to nearly all levels of government and all policy sectors. In his literature review, Steffek (2019) focused on the proceduralist underpinnings of throughput legitimacy, its added value compared to input and output legitimacy, and its normative implications rather than on lessons learned from empirical investigations. Another issue was the lack of indications regarding the methodology. One could only assume that his review was not systematic in the sense of Higgins and Green (2011, Section 1.2.2): "A systematic review attempts to collate all empirical evidence that fits prespecified eligibility criteria in order to answer a specific research question. It uses explicit, systematic methods that are selected with a view to minimizing bias, thus providing more reliable findings from which conclusions can be drawn and decisions made." In addition, our bibliographic search pointed out that the years 2018 and 2019 accounted for more than half of the stock of knowledge on throughput legitimacy, with 45 new publications with the keyword in their metadata. This finding calls for an updated literature review. In our view, for all these reasons, the pioneering work of Steffek constitutes a good starting point. It led us to concentrate on empirical investigations of the production of throughput legitimacy in order to draw theoretical and methodological lessons from them using a systematic literature review method. It also provided us with a series of hypotheses. Would we find the literature on throughput legitimacy to be divided into the same clusters? Would we find the same publications to be influential?

The objective of this article is twofold. From a theoretical standpoint, we want to make sense of the stock of accumulated knowledge on throughput legitimacy, and to map what is already known and what is still debated and unknown. This requires identifying how scholars use and operationalise the concept and what their research question, theoretical framework, methods, and empirical work are. From a methodological standpoint, we want to demonstrate the potential of a systematic literature strategy based on a combination of a quantitative text analysis of abstracts (QTA), a citation network analysis (CNA), and a content analysis of the full text of a sample of publications.

Based on these analyses, we argue that the literature on throughput legitimacy evolves around four lines of questioning. Beyond the theoretical, normative discussion on the constitutive principles of throughput legitimacy (1), scholars have developed indicators to measure its level (2). Others have empirically investigated which policy activities contribute to the production of this type of legitimacy (3). Still others have explored the relations between throughput legitimacy and collaborative governance (4). The works of Schmidt and Wood (2019) and Steffek (2019) extensively addressed question 1. In this article, we focus on the last three questions and their answers.

In Section 2 of this article, we describe our methods. In Section 3 we successively present the results of the QTA, the CNA, and the content analysis. Finally, in the conclusion section, we discuss our results and their implications for the research on throughput legitimacy.

\section{Methods}

In this section, we describe our methods. In our bibliographic search, we used the Scopus database, as it has a number of advantages compared with the Google Scholar and Web of Science (Harzing \& Alakangas, 2016). We searched for scientific publications with the keyword 'throughput legitimacy' in their metadata (title, abstract, keywords, references) across all journal articles and book chapters in English. Such an approach falls into the previously defined category of systematic literature review methods. Using a single keyword was possible due to the unique, unambiguous and shared nature of the throughput legitimacy concept. The idiom does not belong to everyday language nor to disciplines other than the social sciences. In political science, the term bears only a single meaning - that of a particular mode of production of political legitimacy-despite discussions on the principles behind it. In January 2020, we found 98 scientific publications with the keyword 'throughput legitimacy' in their metadata (our dataset).

We applied three different data analysis techniques to the dataset (or to sections of it). First, we conducted a QTA of the abstracts of all publications with an abstract in the dataset (83). We applied Reinert's method (1990) using IRaMuTeQ. This software first breaks down a set of texts into 'segments.' Using factor analysis, it then classifies the resulting segments into 'clusters' based on their lexical similarity. Clusters are subsets of texts that result from a factor analysis of 'lemmas.' Such an analysis provides an overall picture of the literature on throughput legitimacy by dividing it into a small number of the- 
matic clusters. Using the ranking of a cluster's most frequent terms, one can identify its key concepts, research question, theoretical framework, epistemological stance, methods, and empirical work (Goyal \& Howlett, 2018). This is a prerequisite to identify how scholars use and operationalise the concept and to map what is already known and what is still debated and unknown. In addition, the factor analysis allows for the identification of the abstracts that contribute the most to each thematic cluster. We used this function to determine which publications within the dataset would undergo a full-text content analysis.

Second, we performed a CNA on all publications with citations in the dataset (86). To accomplish this, we used the Gephi software. Our 86 publications dealing with the concept of throughput legitimacy referred to 4,229 academic writings. We removed from our list of citations the grey literature and academic writings that were cited by fewer than two of our original 86 publications, as they most likely had little to do with throughput legitimacy. In the network analysis, we focused on three centrality measures. First, the in-degree score of a publication corresponds to its number of citations within the network. Second, the higher the eigenvector centrality score of a publication, the more cited it is by well-cited publications. This measure may be used to determine the most influential publications within a network. Third, the betweenness centrality measures how important a publication is to the shortest citation paths throughout the network. Publications with a high betweenness centrality score are the most likely to combine different theoretical frameworks or methods and to display the most innovative and fruitful findings (Baggio, Brown, \& Hellebrandt, 2015). For each of the three centrality measures, we identified the publications with the highest scores-those that would be the subject of a full-text content analysis.

Third, we conducted a full-text content analysis of a sample of publications resulting from the QTA and the CNA. The sample consists of the publications which contribute the most to each cluster and with the most occurrences of throughput legitimacy in their content (Table 2). In addition, we examined the publications with the highest in-degree, eigenvector-centrality, and betweennesscentrality scores (Table 3 ). The sample amounts to 23 different publications. For the analysis of the sample, we used the NVivo software. Our analysis grid included a number of codes (e.g., the publication's research question, theoretical framework, method, theoretical and methodological lessons). Such a grid allowed for the thorough extraction of answers to our questions.

\section{Results}

\subsection{Quantitative Text Analysis of Abstracts}

Applying Reinert's method resulted in the classification of 83 abstracts into three different clusters. In this sub- section, we describe each cluster using two rankings: the cluster's most frequent terms (Table 1) and most contributing abstracts (Table 2). On this basis, we identify a series of questions for which answers can be found in the existing stock of knowledge.

According to the ranking of its most frequent terms, Cluster 1 focuses on how network and knowledge management may benefit to the achievement of the objectives of subnational environmental projects through a normative, applied, empirical approach. The cluster primarily addresses networks. Here, scholars investigate the management of the relationships among a wide range of actors. They emphasize those who have a managing role: whether they are in charge of managing the network as a whole or knowledge flows. Links may be formal or informal. They may take place inside networks and/or across their boundaries. The aim of Cluster 1 scholars is to prevent negative relationships and to encourage collaborative relationships that allow for learning. For them, positive relationships are intended to increase the effectiveness of projects and the achievement of project objectives. The projects referred to belong to the domain of environmental policies, with a focus on two countries. Cluster 1 scholars analyse the countries at a subnational level rather than at a national level. From a methodological perspective, scholars use quantitative methods, such as surveys, as well as qualitative methods, such as case studies. Cluster 1 belongs to the subfield of environmental policies according to the ranking of its most contributing abstracts. Most of the latter were published in journals pertaining to environmental policies.

Cluster 2 consists of a theoretical, normative, and exclusive discussion on the content of IOs' production process of throughput legitimacy. The cluster's first theme is legitimacy and its different modes of production in democratic systems. Here, the main research question is that of the content of throughput legitimacy: how IOs produce legitimacy in the eyes of citizens in the context of regulation. Cluster 2 scholars discuss the principles behind the concept. They also debate the activities through which these principles are translated into actions. Cluster 2 represents a primarily theoretical discussion. This debate has a normative component. This accounts for the almost complete absence of methodological and empirical terms. Cluster 2 is located at the intersection of various political science subfields according to the ranking of its most contributing abstracts. Some of them were published in journals from subfields such as public administration, IR, EU studies and political economy. Others belong to mainstream political science journals.

Like Cluster 2, Cluster 3 concentrates on how IOs produce throughput legitimacy. In Cluster 3, however, the focus is more on the sequence of actions and their consequences. In addition, the discussion is less theoretical. It is also more open to other conceptual frameworks. Like Cluster 2, Cluster 3 deals with the production of legitimacy. Other similarities are that the scholars in both 
Table 1. Most frequent terms of each cluster.

\begin{tabular}{|c|c|c|}
\hline Cluster & $\begin{array}{c}\text { Percentage of } \\
\text { categorised } \\
\text { segments }\end{array}$ & Terms \\
\hline 1 & $37 \%$ & $\begin{array}{l}\text { Network, water, management, trust, boundary, local, knowledge, performance, strategy, } \\
\text { resource, broker, manager, stakeholder, connective, communication, quantitative, outcome, } \\
\text { effective, environmental, goal, project, multi, federal, realize, research, structure, base, } \\
\text { relationship, span, informal, work, public, organizational, conflict, evolution, numb, natural, } \\
\text { river, mediate, grow, creation, basin, impact, role, challenge, arrangement, large, survey, } \\
\text { regional, formal, community, integrate, system, learn, collaborative, highly, cross, protection, } \\
\text { directive, metric, landscape, transboundary, Norway, collect, area, scarcity, participant, } \\
\text { interorganizational, expansion, crucial, bottom, anchorage, create, influence, datum, private, } \\
\text { collaboration, Netherlands, council, company, manage, idea, important, case, result, sector, } \\
\text { method, evidence, complex, scale, link, field, paper, study, governance, approach, degree, } \\
\text { act, year, leadership, range, provide, prospect, face, plan, order, positive, increasingly, } \\
\text { literature, condition, medium }\end{array}$ \\
\hline 2 & $35 \%$ & $\begin{array}{l}\text { Legitimacy, input, throughput, output, argue, discourse, democracy, transparency, } \\
\text { accountability, analyse, lack, food, inclusiveness, service, procedure, legitimate, critical, } \\
\text { consultation, efficacy, deliberative, concept, criterion, importance, normative, theory, IOs, } \\
\text { rely, weaken, authorization, openness, bureaucracy, share, citizen, term, good, scholar, norm, } \\
\text { generate, highlight, horizontalization, vary, contemporary, agri, substance, reality, emerge, } \\
\text { trade, change, off, gap, gain, regulatory, global, institutional, regulation, deliberation, form, } \\
\text { democratic, lead, nation, low, draw, evaluation, enhance, stealth, responsiveness, standard, } \\
\text { procedural, mean, representative, reach }\end{array}$ \\
\hline 3 & $28 \%$ & $\begin{array}{l}\text { EU, sport, european, issue, commission, crisis, open, supranational, dialogue, investigate, } \\
\text { article, perspective, agent, socio, domestic, eurozone, clear, pressure, mistrust, legitimation, } \\
\text { esos, review, include, economic, member, conduct, process, deficit, coalition, ownership, } \\
\text { cultural, opportunity, hydraulic, fracture, special, player, pathway, union, participatory, } \\
\text { development, build, semester, Europe, basis, legislative, current, time, examine, reform, aim, } \\
\text { social, international, national, state, government, rule, activity, start, mine, undermine, } \\
\text { dilemma, actor, institution, improve, framework, contribution, assess, foster, benefit, } \\
\text { significant, move, effort, drive, finding, politics, establish, parliament, identity, threat, } \\
\text { reinforce, law, information, bring, scope, peer, omc, legislation, integration, illustrate, house, } \\
\text { future, forward, specifically, post, politicization, initiative, force, element, dynamic, advance }\end{array}$ \\
\hline
\end{tabular}

clusters investigate the production process of throughput legitimacy and that they rely on the premise of a legitimacy deficit of IOs. Nevertheless, there are differences between the two clusters. First, Cluster 3 scholars concentrate on IOs and their member states, while Cluster 2 scholars focus on IOs and citizens. In Cluster 3, the emphasis is on the activities necessary to produce throughput legitimacy: participation and access to information rather than on the constitutive principles of the concept. Another difference is that throughput legitimacy is attached to other concepts. Dialogue is considered an intermediary step in the production process of throughput legitimacy, while the latter is understood as affecting the producer's identity and power. Finally, a significant dissimilarity is that Cluster 3 is not limited to a theoretical discussion. Cluster 3 scholars focus primarily on the European level. Therefore, EU institutions occupy a prominent place. Scholars concentrate on a series of economic sectors that include sport policies and extractive industries. No reference to a particular method can be found in Cluster 3. Cluster 3 belongs to the subfield of EU studies according to the ranking of its most contributing abstracts. Most of the latter were published in journals pertaining to EU studies.

In his 2019 literature review, Steffek (2019) divided the literature on throughput literature into three clusters according to their subfield (transnational governance research, EU studies, local governance research), which he inferred from their object of study. Applying Reinert's method resulted in a more fine-grained classification of the literature into three thematic clusters-each with its own research questions, theoretical framework, methods, and empirical work. Throughput legitimacy raised a series of research questions in addition to the theoretical, normative principles behind the concept (Cluster 2). Which policy activities contribute to the production of throughput legitimacy (Cluster 3)? How does throughput legitimacy relate to collaboration between policy actors (Cluster 1)? From this, we inferred a methodological question: Which indicators have proven useful for mea- 
Table 2. Most contributing abstracts to each cluster.

\begin{tabular}{|c|c|c|c|c|}
\hline Cluster & Abstract reference & Journal & $\begin{array}{l}\text { Contribution } \\
\text { to cluster } \\
\text { (Chi2) }\end{array}$ & $\begin{array}{l}\text { Occ. of } \\
\text { 'Throughput } \\
\text { Legitimacy' }\end{array}$ \\
\hline \multirow[t]{10}{*}{1} & Boaventura et al. (2016) & Journal on Chain and Network Science & 14,0 & 1 \\
\hline & $\begin{array}{l}\text { van Meerkerk, Edelenbos, } \\
\text { and Klijn (2015)* }\end{array}$ & Environment and Planning $C$ & 12,2 & 49 \\
\hline & $\begin{array}{l}\text { Matti, Lundmark, } \\
\text { and Ek (2017)* }\end{array}$ & Water Policy & 10,4 & 2 \\
\hline & van Enst et al. (2017) & Sustainability & 10,4 & 1 \\
\hline & Song et al. (2019) & Global Environmental Change & 9,0 & 1 \\
\hline & Michels (2016) & Water Policy & 8,7 & 1 \\
\hline & Muller (2018) & Regional Environmental Change & 8,7 & 1 \\
\hline & Hovik and Hanssen (2016) & Journal of Environmental Policy and Planning & 6,9 & 1 \\
\hline & $\begin{array}{l}\text { Edelenbos and } \\
\text { van Meerkerk (2015)* }\end{array}$ & Current Opinion in Environmental Sustainability & 6,9 & 4 \\
\hline & $\begin{array}{l}\text { Eckerd, Bulka, Nahapetian, } \\
\text { and Castellow (2019)* }\end{array}$ & Critical Policy Studies & 5,2 & 5 \\
\hline \multirow[t]{10}{*}{2} & $\begin{array}{l}\text { Strebel, Kübler, and } \\
\text { Marcinkowski }(2019)^{*}\end{array}$ & European Journal of Political Research & 17,3 & 8 \\
\hline & Behringer and Feindt (2019)* & Politics and Governance & 13,4 & 22 \\
\hline & Schmidt (2013)* & Political Studies & 9,5 & 22 \\
\hline & Klika (2015) & Politics and Governance & 7,6 & 10 \\
\hline & Lettanie (2019) & Journal of Economic Policy Reform & 7,6 & 7 \\
\hline & $\begin{array}{l}\text { Corbett, Yi-Chong, and } \\
\text { Weller }(2018)^{*}\end{array}$ & Cambridge Review of International Affairs & 7,6 & 32 \\
\hline & Steffek (2019)* & Public Administration & 7,6 & 68 \\
\hline & Schmidt and Wood (2019)* & Public Administration & 7,6 & 72 \\
\hline & Boswell and Corbett (2018) & Political Studies & 7,6 & 1 \\
\hline & Falleth et al. (2010) & European Planning Studies & 6,3 & 5 \\
\hline \multirow[t]{10}{*}{3} & Neville and Weinthal (2016) & Review of Policy Research & 13,0 & 1 \\
\hline & Munta (2020)* & European Politics and Society & 13,0 & 33 \\
\hline & Yilmaz (2018) & International Journal of Sport Policy & 13,0 & 1 \\
\hline & $\begin{array}{l}\text { Fromage and } \\
\text { van den Brink (2018) }\end{array}$ & Journal of European Integration & 13,0 & 8 \\
\hline & Kratochvíl and Sychra (2019) & Journal of European Integration & 13,0 & 4 \\
\hline & Geeraert (2014)* & Journal of Contemporary European Research & 10,4 & 24 \\
\hline & $\begin{array}{l}\text { Carstensen and } \\
\text { Schmidt }(2018)^{*}\end{array}$ & Review of International Political Economy & 10,4 & 24 \\
\hline & Poelzer (2019)* & Environmental Science and Policy & 4,5 & 22 \\
\hline & Geeraert and Drieskens (2017) & Journal of European Integration & 4,4 & 1 \\
\hline & Curry $(2016)^{*}$ & Journal of European Social Policy & 4,4 & 23 \\
\hline
\end{tabular}

Note: ${ }^{*}=$ Papers included in the full-text content analysis.

suring the level of throughput legitimacy? To identify where answers can be found to the last three questions, we used a sample of publications from the three clusters and the CNA.

\subsection{Citation Network Analysis}

The CNA of all publications with citations in the dataset (86) resulted in a network of 687 publications con- 
nected by 1,841 citation links. In this subsection, we present three rankings: the publications with the highest in-degree centrality, eigenvector centrality, and betweenness centrality scores (Table 3 ). This analysis provides us with a series of leads on where to find answers to our research questions.

First, we examine the most influential publications in the literature on throughput legitimacy. In line with Steffek (2019), we find among them the pioneering reflexion of Scharpf $(1997,1999)$ on the two modes of production of democratic legitimacy, and the subsequent work of Benz and Papadopoulos (2006) on the application of democratic standards to multilevel governance arrangements. We also find the conceptual work of Risse and Kleine (2007) and Schmidt (2013) on the constitutive principles of throughput legitimacy. Unlike Steffek, our CNA indicates that the reflexion of Greenwood (2007) on the influence of organised civil society interests in the production of legitimacy in the EU counts as one of the most influential publications on throughput legitimacy.

To a certain extent, the ranking of the most influential publications overlaps with one of the most cited publications. The works of Scharpf $(1997,1999)$, Risse and Kleine (2007), and Schmidt (2013) also fall into this second category. Among the most cited publications on throughput legitimacy, we find two journal articles that were absent from Steffek's work. The first is van Meerkerk et al. (2015) investigation of the relation between the connective management of stakeholders, throughput legitimacy, and network performance in the governance of water projects in the Netherlands. The second is Ansell and Gash's (2008) review on the conditions for success of collaborative governance.

Finally, we examine the most bridging publications in the literature. In this ranking, we again find the works of Schmidt (2013) and van Meerkerk et al. (2015). In line with Steffek, we find the studies of lusmen and Boswell (2017) and Hartmann and Spit (2016). While the former discusses the limitations of the pursuit of throughput legitimacy by European and British technocratic bodies, the latter points to the growing role of throughput legitimacy in flood risk management at the European level. Although absent from Steffek's work, the qualitative analysis of Fischer and Schläpfer (2017) on the influence of meta-governance strategies at the forum level on the production of joint position papers counts as one of the most bridging publications. The results of our CNA confirm some of Steffek's (2019) findings and the central role of a number of publications in the literature on throughput legitimacy. In addition, such results indicate that a few other publications may prove useful in answering our research questions.

\subsection{Full-Text Content Analysis}

In this subsection, we describe the results of the content analysis of the full text of a sample of publications resulting from the QTA and the CNA (23). The subsection is organised according to the research questions identified through the QTA: Which indicators have proven useful for measuring the level of throughput legitimacy? Which policy activities contribute to the production of throughput legitimacy? How does throughput legitimacy relate to collaboration between policy actors?

\subsubsection{Which Indicators Have Proven Useful for Measuring the Level of Throughput Legitimacy?}

Surprisingly, only a small number of scholars (eight) measured the level of throughput legitimacy. Among the ones who did not, some are located in Cluster 2 (or cited by Cluster 2 scholars) and engaged in the theoretical discussion on the constitutive principles and/or the added value of the concept (e.g., Risse \& Kleine, 2007; Schmidt \& Wood, 2019). Some others are Cluster 1 scholars (or publications cited by them) who developed arguments on collaborative governance (e.g., Ansell \& Gash, 2008; Fischer \& Schläpfer, 2017). Finally, some publications used throughput legitimacy as a peripheral concept or provided limited information on the operationalisation of the concept (e.g., Eckerd et al., 2019; Hartmann \& Spit, 2016). Going back to scholars who measured the level of throughput legitimacy, indicators vary in numberfrom 2 (Curry, 2016) to 12 (Geeraert, 2014). All of them derive from one (or more) of the constitutive principles behind the concept. However, from one scholar to another, the same indicator may serve two different principles. In an effort to provide a clear and exhaustive analysis of the indicators, we present them according to the concrete features of the decision-making process that they actually measure: the criteria for inclusion, the

Table 3. Publications with the highest centrality scores.

\begin{tabular}{llllll}
\hline \multicolumn{2}{c}{$\begin{array}{c}\text { Most cited publications } \\
\text { within corpus (Indegree) }\end{array}$} & \multicolumn{1}{c}{$\begin{array}{c}\text { Most influential publications } \\
\text { (Eigencentrality) }\end{array}$} & $\begin{array}{c}\text { Most bridging publications } \\
\text { (Betweenesscentrality) }\end{array}$ \\
\hline Schmidt (2013) & 35 & Scharpf (1999) & 1,00 & Schmidt (2013) & $1,90 \mathrm{E}+09$ \\
Scharpf (1999) & 31 & Risse and Kleine (2007) & 0,84 & van Meerkerk et al. (2015) & $1,12 \mathrm{E}+09$ \\
van Meerkerk et al. (2015) & 17 & Greenwood (2007) & 0,66 & lusmen and Boswell $(2017)$ & $3,25 \mathrm{E}+08$ \\
Risse and Kleine (2007) & 13 & Schmidt (2013) & 0,64 & Hartmann and Spit (2016) & $6,58 \mathrm{E}+07$ \\
Ansell and Gash (2008) & 12 & Benz and Papadopoulos (2006) & 0,64 & Fischer and Schläpfer (2017) & $4,88 \mathrm{E}+07$ \\
\hline
\end{tabular}


capacities and roles of decision-makers and stakeholders, the rules supporting the process, and information use and production.

A first set of indicators concentrates on the criteria for inclusion in the decision-making process (and thus provides information on its inclusiveness). For a process to be inclusive, there should be numerous stakeholders (van Meerkerk et al., 2015) and diverse stakeholders in terms of organisational affiliations and policy preferences (Matti et al., 2017). Some scholars specify the particular actors who should be included: those who are potentially the most affected by the policy under discussion (Geeraert, 2014) and administrative elites who have decision-making power (Matti et al., 2017). For Geeraert (2014), the question of who participates in the decisionmaking process should be open to discussion (and new actors should be able to join the process at a later stage).

Other indicators focus on the capacities and roles of the decision-makers and stakeholders in the decisionmaking process. For purposes of inclusiveness and accountability, stakeholders should be granted a seat at the table and the opportunity to present their arguments (which in turn may influence the result of the process; Geeraert, 2014). Stakeholders and decisionmakers should have equal capacities in the process (Munta, 2020), especially in the negotiation phase (Geeraert, 2014). For decision-makers to be accountable, they should consider stakeholders' concerns and inputs (Geeraert, 2014; lusmen \& Boswell, 2017; Munta, 2020). Decision-makers should also explain and justify the result of the process to make it transparent (Geeraert, 2014; van Meerkerk et al., 2015). Finally, the managers of the decision-making process should give more or less room for self-organisation to stakeholders at certain times during the process (Geeraert, 2014).

Another series of indicators concentrates on the formal and informal rules that support the capacities and roles of actors in the decision-making process. For some scholars, the process should follow a predefined, explicit mandate and procedure for purposes of efficacy and quality of deliberation (Geeraert, 2014; Matti et al., 2017). However, for others, inclusiveness and quality of deliberation require stakeholders to be able to shape the agenda and participatory mechanisms and thus to be able to change the mandate and procedure (Iusmen $\&$ Boswell, 2017). The process should provide room for an open, honest discussion (Curry, 2016; Geeraert, 2014; Poelzer, 2019; van Meerkerk et al., 2015). In other words, deliberation should be governed by a 'democratic ethos' (Geeraert, 2014, p. 315), and actors should demonstrate "an ability to listen, account for, and act upon the interest of others" (Poelzer, 2019, p. 34). Such indicators are used to gauge the extent to which the process complies with a variety of principles: inclusiveness, accountability, efficacy, quality of deliberation.

Finally, the last set of indicators focuses on the information produced and used by decision-makers and stakeholders throughout the decision-making process. Such indicators are mostly used to assess the transparency of the process. Decision-making is deemed transparent when stakeholders have access to the information and supporting materials used throughout the process (Poelzer, 2019; Strebel et al., 2019). This may include information on the policy under discussion (van Meerkerk et al., 2015) or on the rules governing the process (Geeraert, 2014). The information that is used should be explained and justified by the decision-makers (Poelzer, 2019). Stakeholders' informational input should be taken into consideration by decision-makers (Munta, 2020), and, beyond this, information used should be coproduced by decision-makers and stakeholders (Curry, 2016; Munta, 2020).

Most scholars do not explore all dimensions of throughput legitimacy. Iusmen and Boswell (2017), Matti et al. (2017) and Munta (2020) mainly concentrate on the quality of participation. Strebel et al.'s (2019) primary focus is on transparency; Curry (2016) concentrates on openness and transparency; Poelzer (2019) on transparency, accountability and responsiveness; Geeraert (2014) on inclusiveness and openness to civil society, transparency and accountability, and efficacy; and van Meerkerk et al. (2015) on inclusiveness and openness transparency and due deliberation.

In most cases, indicators take the form of a dichotomous variable (a yes/no question whose answer is supported by case study material). Exceptions are van Meerkerk et al. (2015) and Matti et al. (2017), who put stakeholders' perceptions at the centre of the measurement of throughput legitimacy and ask them to express their agreement with items using a Likert scale.

In summary, the measurement of throughput legitimacy introduces a number of problems. First, scholars do not systematically measure throughput legitimacy using indicators. Second, when they do so, they use different, sometimes contradictory, sets of indicators. Third, the indicators vary both in number and in quality. Some scholars measure all dimensions of throughput legitimacy, while others only measure some of them. These problems prevent the comparison of findings across empirical case studies of governance processes and going forward in the theory of democratic legitimacy.

\subsubsection{Which Policy Activities Contribute to the Production of Throughput Legitimacy?}

In this paragraph, we strive to only use the previous research works: the ones based on an explicit, multidimensional measurement of the level of throughput legitimacy. If not, this is reflected in the formulation and the implications of the findings. Scholars have identified a number of participatory decision-making activities that contribute to the production of throughput legitimacy. Engaging in such activities is not without risks, as their failure is likely to increase the legitimacy deficit. In other words, producing throughput legitimacy is not only a question of which activities to implement but also of how 
they should be implemented. A number of lessons can be drawn from the literature on collaborative governance.

Activities that contribute to the production of throughput legitimacy have characteristics in common: They are linked to the decision-making process (thus including governance networks and arrangements) and participatory in the sense that they include actors affected by the policy under discussion (stakeholders). At the national and subnational levels, such activities include roundtables with stakeholders, citizen juries and assemblies, referenda and polls, public hearings and presentations, idea competitions (Hartmann \& Spit, 2016), monitoring processes (Eckerd et al., 2019), and policy forums (Fischer \& Schläpfer, 2017; e.g., food policy councils [Behringer \& Feindt, 2019]). At the supranational level, activities that contribute to the production of throughput legitimacy are mostly part of pre-existing IOs' arrangements (Corbett et al., 2018; Curry, 2016; Geeraert, 2014; Munta, 2020).

Interestingly, Hartmann and Spit's (2016) literature review suggests that different types of activity may maximise compliance with different principles of throughput legitimacy. Co-decision mechanisms (roundtables with stakeholders) may increase public support and consensus for the policy under discussion and maximise the inclusiveness and transparency of the decision-making process. This is also the case for public hearings, which may help inform (and educate) citizens and give them a sense of belonging to the citizenry. When consensus is difficult to reach, mechanisms that allow a majority of citizens to choose between predefined policy solutions (referenda) may help justify a controversial policy. Such activities may best serve the principles of legality and accountability. Citizen juries and idea competitionswhich allow the table actors to generate the best ideasmay improve the quality of the final decision, i.e., the quality of the deliberation. Recent research works tend to support Hartmann and Spit's classification. In her case study of European Semester Officers, Munta (2020) demonstrates that their discussions with member state authorities and stakeholders (top-down roundtables oriented towards information exchange) increased ownership and domestic support for European Semester reforms. At the same time, European Semester Officers failed to convey domestic actors' feedback in a way that influenced the EU decision-making process (and improves the quality of deliberation). Thus, the connection between the types of activities implemented and the dimensions of throughput legitimacy maximised should be further explored.

Undertaking activities that contribute to the production of throughput legitimacy is not without risks. As Hartmann and Spit (2016) point out in their review, bringing all actors affected by a certain policy at the table does not automatically solve conflicts. Based on their case studies of the British NHS Citizen initiative and the EC Forum on the Rights of the Child, lusmen and Boswell (2017) demonstrate that activities may be subject to stakeholders' attempts at disruption, which may result in decision-makers' tighter, more top-down control of discussions and increased scrutiny from participants and external observers. The latter situation is likely to paralyse the whole governance process. To prevent disruption, decision-makers may engage in behindthe-scenes negotiations with stakeholders, which would negate the primary purpose of participatory activities. This echoes Greenwood's (2007) argument that the participation of organised civil society interests in EU governance can be considered a complementing democratic input but also an aggravating democratic deficit problem-favouring the asymmetries of power between stakeholders. It is also in line with Corbett et al.'s (2018) study of six IOs, which states that IOs should maintain the balance between inclusiveness and efficiency when including small states in their decision-making activities as an attempt to increase their throughput legitimacy.

Further, some scholars, including lusmen and Boswell (2017), contend that tokenistic participatory activities may instead increase cynicism among stakeholders and amplify the legitimacy deficit. Based on a comprehensive, multidimensional measurement of throughput legitimacy (see supra), Geeraert's (2014) case study of the European social dialogue in professional football shows that a decrease in throughput legitimacy has repercussions on input and output legitimacy. Overall, the previous studies confirm Schmidt's (2013) hypothesis that the production (or nonproduction) of throughput legitimacy has an influence on the production of input and output legitimacy (with the exception of Curry [2016], whose analysis rests upon a bidimensional measure of the concept; see supra). Although not in our original sample, Doberstein and Millar's (2014) comparison of homelessness governance networks in two Canadian cities confirms Schmidt's (2013) hypothesis. These authors find that the failure and discrediting of a governance process undermines the overall legitimacy of the institution behind the process. This decrease in throughput legitimacy may in turn diminish input and output legitimacy. Doberstein and Millar (2014) find the reverse to also be true.

In view of these risks, a number of scholars have begun to connect the concept of throughput legitimacy with the literature on collaborative governance. On the topic, Ansell and Gash's (2008) meta-analysis of 137 cases of collaborative governance constitutes a reference in our sample of publications. Ansell and Gash (2008) identified and categorised a number of conditions for the success of governance processes: favourable prior conditions (e.g., balance between resources of stakeholders; a past history of cooperation); conditions that relate to the governance process itself (e.g., facilitative leadership may; clear rules); intermediate outcomes conditions, i.e., conditions that are endogenous to the process and that interact with each other over time (e.g., trust building, commitment to-and ownership of-the process). One limitation in their work is that some conditions 
can alternatively support or undermine the quality of collaboration (prior conflict and policy deadlock may create an impetus for collaboration).

Looking beyond conditions for throughput legitimacy, a number of scholars have demonstrated that some governance strategies are associated with increased throughput legitimacy. Their research tests and refines Ansell and Gash's (2008) intermediate outcome conditions and highlights the role of horizontalisation and boundary spanning leadership strategies. Poelzer (2019) demonstrates that horizontal interactions between stakeholders foster throughput legitimacy in the context of mine development in Canada and Sweden. Van Meerkerk et al.'s (2015) survey of participants of 166 Dutch complex water projects confirms that throughput legitimacy mediates the relationship between connective management activities and the performance of network governance. More connective management activities and strategies (for network managers to consider the diversity of stakeholders' perceptions and to encourage them to engage with one another) leads to increased throughput legitimacy. More throughput legitimacy in turn leads to better performance of the governance network (network outcomes integrate inputs from actors with different backgrounds). In this case, throughput legitimacy acts as an intermediary outcome. A similar argument is developed by Edelenbos and van Meerkerk (2015), who find that boundary spanning leadership is needed to turn trust-based informal network spaces into collaborative processes where stakeholders can build integrated solutions (which in turn increases throughput legitimacy). Finally, Fischer and Schläpfer (2017), based on the analysis of 29 Swiss environmental policy forums, point out that effective collaboration between stakeholders does not require conditions but combinations of conditions. They find that the most collaborative and productive policy forums are characterised by a bottom-up logic, participation of public authorities, a small number of relatively homogeneous participants, and majority rule. In other words, meta-governance strategies based on the self-organisation of policy actors and a moderate hierarchy foster effective collaboration and the production of throughput legitimacy. The previous research has paved the way for a better connection between combinations of conditions for the success of meta-governance strategies and the production of throughput legitimacy.

\section{Conclusion}

The objective of this article was twofold: to demonstrate the potential of a systematic literature strategy based on a combination of a QTA of abstracts, a CNA, and a content analysis of the full text of a sample of publications; to make sense of the stock of accumulated knowledge on throughput legitimacy, and to map what is already known and what is still debated and unknown.

From a methodological standpoint, the combination of a QTA, a CNA, and a content analysis of publications- within a mixed-methods-based systematic literature review strategy-allowed us to make sense of the stock of accumulated knowledge on throughput legitimacy. First, the QTA of abstracts derived from the bibliographic search and metadata extraction resulted in the classification of publications into three thematic clusters, each with its own research question, theoretical framework, methods and most representative publications. This classification proved different from Steffek's (2019). Cluster 2 asks which normative principles are behind the concept of throughput legitimacy. Cluster 3 questions which policy activities contribute to the production of throughput legitimacy. Cluster 1 asks how throughput legitimacy relates to collaboration between policy actors. An additional underlying question was how to measure throughput legitimacy. Second, the CNA resulted in the identification of the most cited, the most influential, and the most bridging publications on throughput legitimacy. The results confirmed some of Steffek's (2019) findings while suggesting that a few other neglected publications may be insightful in the study of throughput legitimacy (e.g., Ansell \& Gash, 2008; Fischer \& Schläpfer, 2017; Greenwood, 2007; van Meerkerk et al., 2015). Third, the content analysis of the full text of a sample of publications derived from the QTA and the CNA allowed us to provide some answers to the following questions: Which indicators have proven useful for measuring the level of throughput legitimacy? Which policy activities contribute to the production of throughput legitimacy? How does throughput legitimacy relate to collaboration between policy actors? We believe that the latter demonstrated that this mixed-methods-based systematic literature review strategy could be applied to other political science concepts, provided that they are prominent in the literature (i.e., used in numerous publications) and their meaning is unique, unambiguous and shared among scholars (a counter-example is the knowledge utilisation literature where a number of non-shared concepts such as knowledge, scientific expertise, and policy advice coexist; Caby \& Ouimet, in press).

From a theoretical standpoint, we found that the measurement of the level of throughput legitimacy comes with a number of problems that prevent the comparison of findings across empirical case studies of governance processes. Scholars did not systematically measure the level of throughput legitimacy using indicators. When they did so, they used different, sometimes contradictory, sets of indicators. Some scholars measured the different dimensions of throughput legitimacy, while others did not. A more systematic and rigorous use of a more complete set of precise, specific indicators is necessary to move forward in the theory of throughput legitimacy. In this regard, indicators of stakeholders' perceptions regarding the governance process may constitute a promising avenue.

Despite these limitations, scholars have identified a number of participatory decision-making activities that contribute to the production of throughput legitimacy. 
They include different types of activities that may maximise compliance with different principles of throughput legitimacy. Scholars have found that engaging in such activities is not without risks, as their failure is likely to increase the legitimacy deficit. Overall, their research work confirmed Schmidt's (2013) hypothesis that the production (or nonproduction) of throughput legitimacy influences the production of input and output legitimacy. In view of these risks, a number of scholars have begun to connect the concept of throughput legitimacy with the literature on collaborative governance. They have demonstrated that some strategies and combinations of conditions are associated with increased throughput legitimacy. Further research should explore these connections.

\section{Acknowledgments}

This research was supported by the Belgian Fonds de la Recherche Scientifique (FRS-FNRS; PDR T.0062.18 and CDR J.0003.19). The article was presented at the RECONNECT Conference in Lille organised by Camille Kelbel, Julien Navarro, and Giulia Sandri, and at the Public Policy Research Network in London, at the invitation of Claudio Radaelli. The authors thank the conferences organisers and participants for their insightful comments. We thank Axel Marx for his constructive suggestions. Silvia Fierascu also deserves credit for her support for the CNA. We also thank the anonymous reviewers and academic editors.

\section{Conflict of Interests}

The authors declare no conflict of interests.

\section{References}

Ansell, C., \& Gash, A. (2008). Collaborative governance in theory and practice. Journal of Public Administration Research and Theory, 18(4), 543-571.

Baggio, J., Brown, K., \& Hellebrandt, D. (2015). Boundary object or bridging concept? A citation network analysis of resilience. Ecology and Society, 20(2). http:// dx.doi.org/10.5751/ES-07484-200202

Benz, A., \& Papadopoulos, I. (2006). Governance and democracy: Comparing national, European and international experiences. London: Routledge.

Behringer, J., \& Feindt, P. H. (2019). How shall we judge agri-food governance? Legitimacy constructions in food democracy and co-regulation discourses. Politics and Governance, 7(4), 119-130.

Caby, V., \& Ouimet, M. (in press). Usages politicoadministratifs de l'expertise scientifique [Policymakers and civil servants' utilisation of science expertise]. In S. Jacob \& N. Schiffino-Leclercq (Eds.), Traité de politiques publiques [Public policy analysis handbook]. Brussels: Bruylant.

Carstensen, M., \& Schmidt, V. (2018). Ideational pow- er and pathways to legitimation in the euro crisis. Review of International Political Economy, 25(6), 753-778.

Corbett, J., Yi-Chong, X., \& Weller, P. (2018). Small states and the 'throughput' legitimacy of international organizations. Cambridge Review of International Affairs, 31(2), 183-202.

Curry, D. (2016). The question of EU legitimacy in the Social OMC peer review process. Journal of European Social Policy, 26(2), 168-182.

Doberstein, C., \& Millar, H. (2014). Balancing a house of cards: Throughput legitimacy in Canadian governance networks. Canadian Journal of Political Science/Revue Canadienne de Science Politique, 47(2), 259-280.

Eckerd, A., Bulka, L., Nahapetian, E., \& Castellow, D. (2019). Strategic planning and performance measurement: Engaging the community to develop performance metrics. Critical Policy Studies. https://doi. org/10.1080/19460171.2019.1660904

Edelenbos, J., \& van Meerkerk, I. (2015). Connective capacity in water governance practices: The meaning of trust and boundary spanning for integrated performance. Current Opinion in Environmental Sustainability, 12, 25-29.

Fischer, M., \& Schläpfer, I. (2017). Metagovernance and policy forum outputs in Swiss environmental politics. Environmental Politics, 26(5), 870-892.

Geeraert, A. (2014). New EU governance modes in professional sport: Enhancing throughput legitimacy. Journal of Contemporary European Research, 10(3). https://doi.org/10.30950/jcer.v16i3.1085

Goyal, N., \& Howlett, M. (2018). Lessons learned and not learned: Bibliometric analysis of policy learning. In C. Dunlop, C. Radaelli, \& P. Trein (Eds.), Learning in public policy: Analysis, modes and outcomes (pp. 27-49). Cham: Palgrave Macmillan.

Greenwood, J. (2007). Organized civil society and democratic legitimacy in the European Union. British Journal of Political Science, 37(2), 333-357.

Hartmann, T., \& Spit, T. (2016). Legitimizing differentiated flood protection levels: Consequences of the European flood risk management plan. Environmental Science \& Policy, 55, 361-367.

Harzing, A. W., \& Alakangas, S. (2016). Google Scholar, Scopus and the Web of Science: A longitudinal and cross-disciplinary comparison. Scientometrics, 106(2), 787-804.

Higgins, J., \& Green, S. (2011). Cochrane handbook for systematic reviews of interventions. Chichester: John Wiley and Sons. Retrieved from https://training. cochrane.org/handbook/archive/v5.1/

Iusmen, I., \& Boswell, J. (2017). The dilemmas of pursuing 'throughput legitimacy' through participatory mechanisms. West European Politics, 40(2), 459-478.

Matti, S., Lundmark, C., \& Ek, K. (2017). Managing participation: Prospects for learning and legitimacy- 
creation in Swedish water management, Water Policy, 19(1), 99-114.

Munta, M. (2020). Building national ownership of the European Semester: The role of European Semester officers. European Politics and Society, 21(1), 36-52.

Papadopoulos, Y. (2003). Cooperative forms of governance: Problems of democratic accountability in complex environments. European Journal of Political Research, 42(4), 473-501.

Poelzer, G. (2019). A view from the top: State perspectives on legitimacy and the mine development process. Environmental Science \& Policy, 94, 32-38.

Reinert, M. (1990). Alceste une méthodologie d'analyse des données textuelles et une application: Aurelia De Gérard De Nerval [Alceste: A methodology for text analysis and an illustration: Gerard De Nerval's Aurelia]. Bulletin de Méthodologie Sociologique, 26(1), 24-54.

Risse, T., \& Kleine, M. (2007). Assessing the legitimacy of the EU's treaty revision methods. Journal of Common Market Studies, 45(1), 69-80.

Scharpf, F. (1997). Introduction: The problem-solving capacity of multi-level governance. Journal of European Public Policy, 4(4), 520-538.

Scharpf, F. (1999). Governing in Europe: Effective and democratic? Oxford: Oxford University Press.

Schmidt, V. (2013). Democracy and legitimacy in the European Union revisited: Input, output and 'throughput.' Political Studies, 61(1), 2-22.
Schmidt, V., \& Wood, M. (2019). Conceptualizing throughput legitimacy: Procedural mechanisms of accountability, transparency, inclusiveness and openness in EU governance. Public Administration, 97(4), 727-740.

Steffek, J. (2019). The limits of proceduralism: Critical remarks on the rise of 'throughput legitimacy.' Public Administration, 97(4), 784-796.

Strebel, M.-A., Kübler, D., \& Marcinkowski, F. (2019). The importance of input and output legitimacy in democratic governance: Evidence from a population-based survey experiment in four West European countries. European Journal of Political Research, 58(2), 488-513.

van Meerkerk, I., Edelenbos, J., \& Klijn, E.-H. (2015). Connective management and governance network performance: The mediating role of throughput legitimacy. Findings from survey research on complex water projects in the Netherlands. Environment and Planning C: Government and Policy, 33(4), 746-764.

Zürn, M. (1998). Regieren jenseits des Nationalstaates: Globalisierung und Denationalisierung als Chance [Governing beyond the nation state: Globalization and denationalization as an opportunity]. Frankfurt am Main: Suhrkamp.

Zürn, M. (2000). Democratic governance beyond the nation-state: The EU and other international institutions. European Journal of International Relations, 6(2), 183-221.

\section{About the Authors}

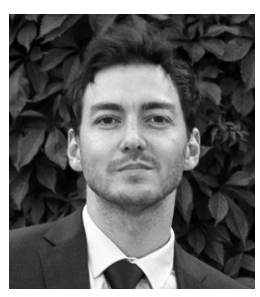

Vincent Caby works as a Postdoctoral Research Fellow at UCLouvain. He holds a PhD in Political Science from Sciences-Po Bordeaux. His research work deals with the institutionalisation of policy advice and scientific expertise: how new forms of expertise become a gold standard in the eyes of policymakers. He addresses the effects of official reports on the policymaking process, and the methodological challenges of investigating policy advice.

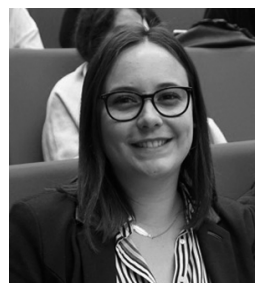

Lise Frehen is a PhD Candidate at the Institute of Political Science Louvain-Europe, Catholic University of Louvain. She is also a Teaching Assistant for the MA in public administration. She has a MA in international relations from Catholic University of Louvain. She currently works on the use of information by policymakers, especially at the EU level. 